\title{
The Influence of Remittances on Education and Health Outcomes: an Analy- sis for South Asian Countries
}

\author{
Sana Ullah ${ }^{* 1}$, Muhammad Tariq Majeed ${ }^{2} \&$ Adiqa Kausar Kiani ${ }^{3}$ \\ ${ }^{1} 2$ Quaid-i-Azam University, Islamabad, Pakistan \\ ${ }^{3}$ Federal Urdu University, Islamabad, Pakistan
}

\begin{abstract}
Remittances all over the world play significant role in improving the standard of living of the people in general. Broadly it is difficult to analyze all the characteristics of life standards and, usually researcher look at the educational or health indicators, which are the major concerns of every household. In this study, we also explored the effect of international remittances on educational and health indicators for selected South Asian countries. Our findings show that remittances play a vital role in enhancing health attainment for instance, escalating life expectancy, slashing infant mortality and fertility rate. The Two-Stage Least Square (2SLS) technique has been applied. Upshots of our study suggest that flow of remittances is one of the significant sources for economic development. It is viewed that high migration rate effect only health variables but a little improvement has been observed for educational attainment in South Asian region.

Keyword: Remittances, Education, Health, South Asian
\end{abstract}

JEL classification: O11, O15, I10, I20

\section{Introduction}

It is observed that over 200 million people in the world are currently living in a country in which they were not born, a number that is becoming larger with passage of time (Schiantarelli, 2005). These aliens send money to their home countries, known as Foreign Remittances. For most developing countries, a remittance becomes second largest sources of foreign income after Foreign Direct Investment (FDI) (Schiantarelli, 2005). In this situation, some factors have a special importance in a particular community. They are not important source of valuable foreign exchange for the developing countries, but are also a source of poverty reduction and improvement of Physical Quality of Life Index (PQLI) and Human Development Index (HDI).

One stream of well-being they lift the liquidity constraints in to their own community. This is one of the biggest sources which used for health and educational purposes. Remittances really effect to reduce poverty levels, impel educational attainment and subsidize to improve health indicators to great extent (Calero et al., 2009; Gupta et al., 2007; Jongwanich, 2007; Stark et al., 1988; Taylor and Wyatt, 1996). Therefore, it is said that Inflow of remittances reduce the poverty by inspiring the income of the recipient country, removing credit constraints, enhancing investment in education, escalating human development by spending more in-

*Corresponding author.

Email: sanaullah133@yahoo.com come on better health services. In the same context, Duryea et al. (2005) identified that remittances may also use to facilitate housing infrastructure. These physical environment improvements in which families live are thought to contribute toward rebates in infant mortality and fertility rates. Amuedo-Dorantes and Pozo (2011) found that families who spend more remittances to cover their medical expenses have better health facilities than those who do not.

Despite the growing interest in this area, the existing literature is still limited in South Asian countries. Yet, most existing studies focused on Latin American countries and also hidden the education and health indicators issues. In short, all time focus on economic consequences of using remittances and paid very less attention to this area. In general, these ideas have been mostly supported by empirical evidence on migrantsending countries. In this context, we use the South Asian regions in our study to explore the influence or use of remittances on human indicators.

The basic purpose of the paper is to study the impact of remittances on development indicators (education and health) for selected South Asian countries. This study tries to explore whether remittances is a strong instrument influencing and improving education and health indicators or not. Further, how remittances in different countries are used for different purposes and underlying reasons behind them. 


\subsection{Remittances to South Asia: An Overview}

Migrants have become directly and substantively involved in different economic and social activities in their countries. Migration of South Asians to the whole world for work purpose is not a recent phenomenon; Asian migrants have been going around the world for more than three decades. Workers remittances to under-developed countries have experienced a sensational increase in the last few decades. According to the Schiantarelli (2005), in 1990 remittances to low and middle income countries amounted to about US $\$ 30$ billion. It is predicted that after fifteen years this amount would reach approximately up to US $\$ 170$ billion, i.e. $\$ 10$ billion increase every year for the next fourteen/fifteen years.

There is a long history of labor migration from South Asia to various parts of the world. Today Asians workers are operating their working duties brightly overall the World, especially in UAE, Europe and USA etc. Because these labor markets have low size of population, these nations have great possibility to appeal labor force from numerous sides of the world. Due to the easy migration to the labor market of these countries, majority of Asians skilled and unskilled force perform their duties in these countries. $\$ 63.82$ billions India is the highest among South Asian who receive remittances whereas Bangladesh is lowest $\$ 15.8$ billions. Pakistan is $8^{\text {th }}$ largest among South Asian regions who receive remittances i.e. $\$ 20.1$ billion. In the decade of 1980, tremendous increase by remittances to Bangladesh, India and Sri Lanka region but international remittance has increased for Nepal over the last decade. In case of Pakistan, first one and half decades remittance continue to decline and again growing significant instrument after 2000. Figure 1 illustrates this trend.

\section{Literature Review}

Limited studies discussed the issue of influence of remittances on education and health outcomes for South Asian regions; therefore this study is conducted for the purpose to address this issue particularly. Researchers viewed that there is increased trend of migration or remittances sent by migrant to or from South Asian countries, but limited work has been found on human development in the context of remittances. However, educational and health position of children that belonging to migrant households. Recent empirical studies highlight the linkage between education and health outcomes due to remittances and however, these results are not captured due to the lack of accurate data in South Asian regions, and most of the work is yet not completed.
In our study, effects of remittances on education and health have been examined. We obtained the data of remittances on household level and discussed the patterns of remittances. While related studies concentrate on macro effects in recipient countries including life expectancy, infant mortality rate and fertility rate. In this section, we present only education and health indicators development literature through remittances in various regions but there is enough literature available on this issue internationally. Therefore we discuss briefly different literature cited for developed and developing countries in this study.

Large number of studies has shown that there is an upsurge of average year of schooling of family members due to the overcome the liquidity constraints. Remittances are also lifting the budget constraint of families in latest era that also might raise the expenditure of human capital. New research agenda on remittances and year of education has emphasized the budding performance in developing countries. For instance, Yang (2005) found many children year of schooling in families whose migrants receive larger external finance in Philippines. Dhungana and Pandit (2014) found same result for Nepal; C $\tilde{A}^{3}$ rdova et al. (2004) found same kind of results for Mexico communities in his study.

In case of Haiti, Amuedo-Dorantes and Pozo (2006) tested the hypothesis that remittances raise educational attainment. They found that migrant income affect negatively with household members due to failure of the children enrollment in the school. However, migrant income starts to inflow; they raise the school enrolment and attendance with passage of time. Especially, girls enrolment and attendance appears to be raised from the external finance and secondary school enrolments grow more by the family. Remittances have a significant contribution to educational variables as remittances add emphatically to the attendance, school enrolment and years of schooling.

Dustmann and Glitz (2011) defined the remittances function in these words; they lift the liquidity constraints, enhances investments in human capital of developing countries, students in under-developed nations are often expected to pay for their books, transport, uniforms, food and sometimes even teacher salaries pay from this source. Furthermore, attending school imposes additional costs on the family through with reductions in income or family production by the attendee. See also Elbadawy et al. (2009); Wahba (1996) for Egypt; Jensen and Nielsen (1997) for Zambia; Ilahi (2001) for Peru; Kabki et al. (2003) for West Africa; McKenzie and Rapoport (2006) for Mexico, Acosta et al. (2007) for Latin American countries and Calero et al. (2009) for Ecuador; which provide an extensive discussion on the role of lifting of liquidity constraints. Similarly, Córdova (2006) found positive effect of migration on educational attainment for children in poor families. 
Table 1: Top 10 Remittance-Receiving Countries, 2015

\begin{tabular}{lcc}
\hline No & Country & Remittances (\$US billions) \\
\hline 1 & India & 72.2 \\
2 & China & 63.9 \\
3 & Philippines & 29.9 \\
4 & Mexico & 25.7 \\
5 & France & 24.6 \\
6 & Nigeria & 20.8 \\
7 & Egypt & 20.4 \\
8 & Pakistan & 20.1 \\
9 & Germany & 17.5 \\
10 & Bangladesh & 15.8 \\
\hline
\end{tabular}

Source: Migration and Remittances Fact book, Development Prospects Group, World Bank (2016)

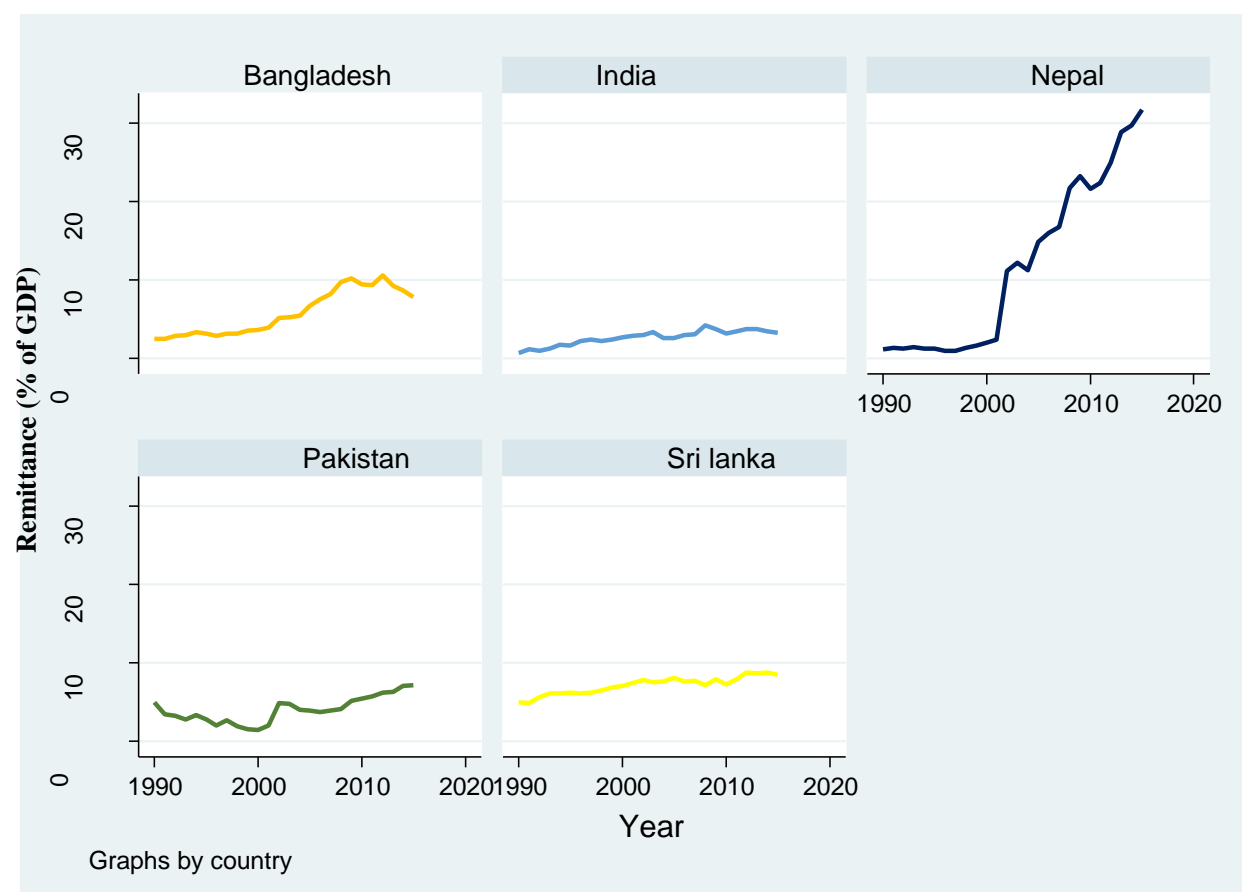

Figure 1: Remittance (\% of GDP) Inflows by Region (1990 2015)Source: World Bank (2016)

In addition, Taylor and Wyatt (1996) viewed that remittances increase the volume of family resources and also increase the maximum years of schooling.

The second part of the literature emphasizes the health indicator improvement through a migrant income. Child health is relatively imperative for the prosperity of community and regulates development of human capital. Starting from Grossman (1972) production model, remittances help to impel child health outcome by the means of purchases of children health care and feed, while migration phenomenon might have significant positive affect child health first through the smaller amount of time spent by parents with their children and this concentration impel with passage of time.

Acosta et al. (2007) analyze the contribution of remittances to Latin America and used a set of health variables in their study. They included, height and weight-for-age of children aged 0 to 1 years and children aged 2 to 5 years. They observed that children aged 0-5 year have been vaccinated. In a nutshell, their analysis shows that children in recipient families enjoy better health facilities. Amuedo-Dorantes and Pozo (2011) analyzed the link between remittances and health care expenses. Furthermore, remittances 
increase health care expenditures and the level of expenditures undertaken. In short, a remittance is a statically significant determinant of health care expenditures, when compared to alternative sources of income. Zhunio et al. (2012) predicted the Mexico societies, found that a $1 \%$ rise in remittances per capita reduced infant mortality rate by $0.15 \%$ and improved life expectancy by $0.03 \%$.

McKenzie and Rapoport (2006) pointed out that migration improves children health outcomes, increasing birth weights and lowering infant mortality, where lots of improvement say, in health variables (infant mortality and birth weights) through a remittance. In addition, it is shown that two further impacts on health; (1) high opportunity cost of time and (2) receive some forms of health inputs. Evidence for this effect is seen in children in migrant households receiving their good feed and full dose of vaccines. A more significant positive influence is observed in terms of parental health knowledge. Mothers in migrant families are found to be a have advanced levels of health information and similarly, knowledge spillovers in non-migrant households mothers.

Hildebrandt and McKenzie (2005) found positive evidence of migration on health outcomes due to remittances increases which show an increase in birth weights and reductions in infant and mortality. Children health is highly correlated with the mother knowledge about health. The paper also provides routes through which these networks affect child health, and it is also revealed that the migration trails can consequence in mounting health information.

This health knowledge enhances the health outcomes through different channels. They find the comparative advantage of the children of migrants and non-migrants, children of migrants household are more fed, and fully vaccinated and taken to a Physician in early year of life. In a nutshell, the overall literature gives the evidence that remittances seem to improve health and educational in particular and improve standard of living of migrants in general. Similarly, Ratha (2013) argues that remittances could play a crucial role as a powerful antipoverty force because they tend to raise the incomes of households in the developing world. In short, remittance may affect health through different channels.

\section{Methodology}

\subsection{Description of Data and Sources}

The data for our empirical model include 5 countries for 26 years data from 1990 to 2015 . Our empirical model includes one educational indicator and three health indicators as dependent variables. For education, we use 1) average year schooling. For health, we use 1) Fertility Rate (number of children that would be born to each woman), 2) Infant Mortality (death rate during the first year of life) and 3) Life Expectancy at Birth.

For consistency, data on education and health dependent variables are obtained from World Development Indicators (WDI) but educational variable is provided by Barro and Lee; independent variables (Education and Health Spending, Physicians, GDP per capita, Unemployment Rate, Rural Population) were obtained using the World Banks World Development Indicators and remaining instrumental variable obtained from World Development Indicators. Table 2 shows the complete list of variables along with their definitions and summary statistics. The complete list of countries used in the analysis is shown in the Appendix.

For each of the dependent variables to be estimated, we include a common set of explanatory and control variables. These includes 1) Remittances (\% GDP), 2) Net Outward Migration, 3) GDP per capita (in 2010 \$US), 4) Unemployment Rate, 5) Rural Population and 6) Infant Mortality Rate (for the education estimates). Further, we include educational and health specific determinants for each respective variable, including 1) Public Education Expenditures (\% of GDP), 2) Public Health Expenditures ( $\%$ of GDP), and 3) Number of Physicians (per 1000 population). For all estimations, we include yearly time variable to capture the time trend not explained with country-specific factors.

Data on educational variable and number of Physicians are available in irregular pattern. Therefore, in order to make them continue for every year from 1990 to 2015 , we extrapolate them using Stata 14 software.

\subsection{Model and Methodology}

This chapter builds up an econometrics framework and informed about suitable methodology. In first part, we describe few applications of the random effect (RE), unobservable individual effect, unobservable time effect and idiosyncratic term in model. This study first uses the Random Effect approach. Similarly, alternative test is Fixed Effect which is based on two main assumptions. First, the intercept is permitted to vary from individual (country) to individual (country) but constant over time. Second, the slope parameters are assumed to be invariable in both dimension (unobservable individual $\left(\mu_{i}\right)$ and time dimensions $((t)$. Same as, Random Effect which is based on two main assumptions slope and intercept are fixed in both unobservable individual and time dimensions and reminder disturbance stochastic with $\epsilon_{i t} \operatorname{IID}\left(0, \sigma_{\epsilon}^{2}\right)$. Another assumption of the Fixed effect model, unobservable individual is the time-invariant but other macro variables are time variant variable.

The Hausman specification test justifies fixed effect and random effect models (Hausman, 1978). If indi- 
Table 2: Definition and Descriptive Statistics

\begin{tabular}{|c|c|c|c|c|c|}
\hline Variables & Definition & Mean & Min & Max & S.D \\
\hline \multicolumn{6}{|l|}{ Dependent variables } \\
\hline Year of schooling & Education index & 4.44 & 2 & 8.63 & 1.88 \\
\hline Life Expectancy & $\begin{array}{l}\text { Number of years from birth if prevailing patterns } \\
\text { of mortality remain constant }\end{array}$ & 65.65 & 54.19 & 74.93 & 74.93 \\
\hline Infant Mortality & $\begin{array}{l}\text { Number of infants dying before reaching one year } \\
\text { of age, per 1,000 live births }\end{array}$ & 55.28 & 7.46 & 106.1 & 28.31 \\
\hline Fertility Rate & $\begin{array}{l}\text { Number of children born to a mother if she lives to } \\
\text { the end of her childbearing years }\end{array}$ & 3.32 & 2.01 & 6.04 & 1.02 \\
\hline \multicolumn{6}{|l|}{ Independent variable } \\
\hline Real Remittances & Remittances (\% of GDP). & 6.27 & 0.73 & 31.75 & 5.93 \\
\hline Public Education Spending & Spending on education ( $\%$ of GDP). & 2.73 & 1.42 & 5.34 & 0.79 \\
\hline Health Spending & Spending on Health (\% of GDP). & 3.86 & 2.14 & 6.72 & 1.15 \\
\hline Number of Physicians & Physicians (per 1,000 people). & 0.46 & 0.04 & 1.26 & 0.25 \\
\hline GDP per capita & GDP per capita (constant 2010 US\$). & 1026.4 & 357.35 & 3637.53 & 703.46 \\
\hline Unemployment Rate & Unemployment, total (\% of total labor force). & 5.22 & 1.4 & 14.7 & 2.62 \\
\hline Rural Population & Rural population (\% of total population). & 75.74 & 61.24 & 91.14 & 7.77 \\
\hline
\end{tabular}

vidual effects are uncorrelated with the other explanatory variables (Ho is accepted), a fixed effect model produces biased estimators, violating one of the GaussMarkov assumptions; so otherwise a random effect model is preferred. When the panel data is balanced, because the same time periods are available for all cross section units; expect fixed effects to work well. Or else, the random effect estimator will be more appropriate (Wooldridge, 2010). Here we will not use the Fixed effect model because there is some problem in the variable, some variable changes are sluggish movement, such as, average year of schooling and life expectancy etc. That is why, Fixed effect model as well as Hausman test is not applicable in this model.

Similarly, A two-way error component model has two group variables, one individual variable $\left(\mu_{i}\right)$ or one time variables $\left(\lambda_{t}\right)$. However, Serrasqueiro and Nunes (2008) argued that developing countries differ in terms of their political regimes, their colonial background, their geographical locations and climatic conditions, their ideologies and religious affiliations etc. these things captured in the forms of unobservable individual $\left(\mu_{i}\right)$. Secondly, it $\left(\lambda_{t}\right)$ could account for strike year effects that disorganize production and affect its price, all of which could affect consumption behavior (Baltagi, 2008).

According to our research question, we are interested to analyze the value of remittances on specific health and education outcomes. For the purpose, we use panel data approach for South Asian countries. The econometric model for the study is specified as follows:

Outcome $_{i t}=\alpha+\beta_{1} R_{i t}+\beta_{x} X_{i t}+u_{i}+\lambda_{t}+\epsilon_{i t}$

Where $\mathrm{R}_{i t}$ represents remittances received by coun- try $\mathrm{i}$ in year $\mathrm{t}$; $\mathrm{Xit}$ is the set of explanatory variables for country $i$ in year t including GDP per capita, rural population, public expenditures on education and health, unemployment rate; $u_{i}$ represents the regional dummies of South Asia Regions (Bangladesh, India, Nepal, Pakistan and Sri Lanka) introduced to control the geographic characteristics in the model; $\lambda_{t}$ represents a time trend variable and $\epsilon_{i t}$ idiosyncratic error. One of the primary issues seen in existing literature is potential endogeneity with respect to remittances. A common critique is that such studies capture correlations between remittances and education and health variables rather than revealing a causal relationship between increased remittances and improved education or health. To address this concern, we employ two econometric models to estimate equation (1) we start with a random effect GLS estimation with a balanced panel data in order to maximize the use of available observations. Complete data is available for all selected countries during the years 1990 to 2015 . We also used the random effects specification as it allows us to use time invariant country level explanatory variables.

Similarly, they also have problem of endogeneity in the random effect equation. However, we solve this problem with the instrumental variables techniques. The econometric model for the study is specified as follows:

$$
\begin{gathered}
\text { Outcome }_{i t} \\
=\alpha+\beta_{x} X_{i t}+\mathrm{U}_{i t}
\end{gathered}
$$

Here $X_{i t}$ have a problem of endogeneity and classical assumption $\operatorname{cov}\left(X_{i t}, \mathrm{U}_{i t}\right)=0$ is dropped. Now this 
Table 3: Random Effects GLS Estimates of the Effects of Remittances on Education and Health

\begin{tabular}{|c|c|c|c|c|}
\hline & Education Indicator & & Health Indicator & \\
\hline \multirow[t]{2}{*}{ Variables } & Average Year of schooling & Life Expectancy & Infant Mortality & Fertility rate \\
\hline & (1) & (2) & (3) & (4) \\
\hline \multirow[t]{2}{*}{ Real Remittances } & $0.0321^{* * *}$ & $0.632^{* * *}$ & $0.632^{* * *}$ & $0.103^{* * *}$ \\
\hline & $(0.0122)$ & $(0.043)$ & $(0.043)$ & $(0.018)$ \\
\hline \multirow[t]{2}{*}{ Education expenditures } & $-0.427^{* * *}$ & & & \\
\hline & $(0.0733)$ & & & \\
\hline \multirow{2}{*}{ Health expenditures } & & 0.364 & 0.364 & $0.474^{* * *}$ \\
\hline & & $(0.315)$ & $(0.315)$ & $(0.133)$ \\
\hline \multirow[t]{2}{*}{ Physicians } & & $11.31^{* * *}$ & $-11.31^{* * *}$ & $-2.771^{* * *}$ \\
\hline & & $(1.970)$ & $(1.970)$ & $(0.830)$ \\
\hline \multirow[t]{2}{*}{ GDP per Capita } & $0.0027^{* * *}$ & $0.0189^{* * *}$ & $0.0189^{* * *}$ & $-0.0038^{* * *}$ \\
\hline & $(0.0002)$ & $(0.001)$ & $(0.001)$ & $(0.0004)$ \\
\hline \multirow{2}{*}{ Unemployment rate } & $-0.0580^{* * *}$ & $-0.093^{*}$ & $-0.093^{*}$ & $-0.045^{* *}$ \\
\hline & $(0.0133)$ & $(0.053)$ & $(0.053)$ & $(0.022)$ \\
\hline \multirow[t]{2}{*}{ Rural population } & 0.0025 & $-0.248^{* * *}$ & $0.248^{* * * *}$ & $0.076^{* * *}$ \\
\hline & $(0.0064)$ & $(0.059)$ & $(0.059)$ & $(0.024)$ \\
\hline \multirow[t]{2}{*}{ Infant mortality } & $-0.046^{* * *}$ & & & \\
\hline & $(0.003)$ & & & \\
\hline \multirow[t]{2}{*}{ Constant } & $6.762^{* * *}$ & $72.92^{* * *}$ & $72.92^{* * *}$ & 1.182 \\
\hline & $(0.832)$ & (3.996) & (3.996) & $(1.684)$ \\
\hline Observations & 125 & 125 & 125 & 125 \\
\hline Number of country & 5 & 5 & 5 & 5 \\
\hline R2 & 0.90 & 0.81 & 0.84 & 0.89 \\
\hline
\end{tabular}

Notes: Standard errors in parentheses. Significance of coefficients at the $10 \%, 5 \%$, and $1 \%$ levels are shown by ${ }^{*},{ }^{* *}$, and ${ }^{* * *}$, respectively.

problem we solve with the two stage least squares (2sls) method. So now, stage 1 equation, we regress $X_{i t}$ on the $z_{i t}$. So, here $Z_{i t}$ is an instrumental variable. That is the good predictor of the $X_{i t}$.

$$
\begin{gathered}
X_{i t} \\
=a+b_{x} z_{i t}+V_{i t} \\
\hat{a}=\overline{x_{i t}} \\
-\hat{b_{x}} \overline{z_{i t}} \\
\overline{x_{i t}}=\hat{a} \\
-\hat{b_{x}} \overline{z_{i t}}
\end{gathered}
$$

Now we move onto the stage 2. So,

$$
\text { Outcome }_{i t}
$$$$
=\alpha+\beta_{x} X_{i t}+U_{i t}
$$

Every solution has some cost. For the problem of endogeneity, it is large problem we create little problem then that will remove the large problem. So for that reason, now we add and subtract $\overline{x_{i t}}$ in the equation that will filter the endogeneity problem and provide the unbiased estimator.
Outcome $_{i t}$

$$
=\alpha+\beta_{x}\left(\overline{x_{i t}}+X_{i t}-\overline{x_{i t}}\right)+U_{i t}
$$

Outcome $_{i t}$

$$
=\alpha+\beta_{x} \overline{x_{i t}}+\beta_{x}\left(X_{i t}-\overline{x_{i t}}\right)+U_{i t}
$$

Outcome $_{i t}$

$$
=\alpha+\beta_{x} \overline{i_{i t}}+\beta_{x}\left(X_{i t}-\overline{x_{i t}}\right)+U_{i t}
$$


Table 4: 2SLS Estimates of the Effects of Remittances (Instrumented) on Education and Health

\begin{tabular}{|c|c|c|c|c|}
\hline \multirow[b]{2}{*}{ Variables } & \multicolumn{2}{|l|}{ Education Indicator } & \multicolumn{2}{|l|}{ Health Indicator } \\
\hline & Average Year of Schooling & Life Expectancy & Infant Mortality & Fertility Rate \\
\hline & (1) & (2) & (3) & (4) \\
\hline \multirow[t]{2}{*}{ Real Remittances } & $0.0656 * *$ & $0.930^{* * *}$ & $-2.908^{* * * *}$ & $-0.0949^{*}$ \\
\hline & $(0.0309)$ & $(0.174)$ & $(0.905)$ & $(0.0588)$ \\
\hline \multirow{2}{*}{ GDP per Capita } & $0.0026^{* * *}$ & $0.0200^{* * *}$ & $-0.088^{* * *}$ & $-0.0015^{* *}$ \\
\hline & $(0.0002)$ & $(0.0020)$ & $(0.010)$ & $(0.0006)$ \\
\hline \multirow[t]{2}{*}{ Education expenditures } & $-0.393^{* * *}$ & & & \\
\hline & $(0.060)$ & & & \\
\hline \multirow[t]{2}{*}{ Health expenditures } & & 0.598 & $-5.736^{* *}$ & $-0.573^{* *}$ \\
\hline & & $(0.493)$ & $(2.558)$ & $(0.266)$ \\
\hline \multirow[t]{2}{*}{ Physicians } & & $-14.61^{* * *}$ & $68.57^{* * *}$ & $2.064^{* *}$ \\
\hline & & $(2.713)$ & $(14.07)$ & $(0.915)$ \\
\hline \multirow{2}{*}{ Unemployment rate } & -0.0030 & 0.053 & $-2.227^{* * *}$ & $-0.0917^{* * *}$ \\
\hline & $(0.0134)$ & $(0.067)$ & $(0.350)$ & $(0.0228)$ \\
\hline \multirow[t]{2}{*}{ Rural population } & $-0.0193^{* * *}$ & $-0.382^{* * *}$ & $1.075^{* *}$ & $0.0702^{* *}$ \\
\hline & $(0.0060)$ & $(0.105)$ & $(0.547)$ & $(0.0355)$ \\
\hline Infant mortality & $\begin{array}{c}-0.0600^{* * *} \\
(0.0037)\end{array}$ & & & \\
\hline \multirow[t]{2}{*}{ year } & $-0.0619^{* * *}$ & -0.046 & $-0.780^{*}$ & $-0.127^{* * *}$ \\
\hline & $(0.0091)$ & $(0.082)$ & $(0.428)$ & $(0.027)$ \\
\hline \multirow[t]{2}{*}{ Constant } & $133.0^{* * *}$ & 173.70 & $1,604^{*}$ & $257.0^{* * *}$ \\
\hline & $(18.46)$ & $(168.5)$ & $(874.3)$ & $(56.84)$ \\
\hline Observations & 125 & 125 & 125 & 125 \\
\hline Number of country & 5 & 5 & 5 & 5 \\
\hline Wald Chi ${ }^{2}$ & 4029.66 & 1281.69 & 1074.65 & 278.12 \\
\hline
\end{tabular}

Notes: Standard errors in parentheses. Significance of coefficients at the $10 \%, 5 \%$, and $1 \%$ levels are shown by $*, * *$, and ${ }^{* * *}$, respectively.

$$
\begin{gathered}
\epsilon_{i t} \\
=\beta_{x}\left(X_{i t}-\overline{x_{i t}}\right)+U_{i t} \\
\text { Outcome }_{i t} \\
=\alpha+\beta_{x} \overline{x_{i t}}+\epsilon_{i t}
\end{gathered}
$$

Lastly, we use instrumental variables; two stage least squares model with our controlled variable estimation. This allows us to address the issues of endogenity; there are the three main causes, omitted variable, measurement errors, simultaneity. We remove omitted variable and simultaneity problem with proxy variable and system of equation; but we employ the 2sls for all problems in panel model. For all of these econometric problems, we can apply instrumental variables approach (2SLS) estimations because instrumental variables are used to remove correlations between the independent variables and error term. This instrumental variable completely holds the instrumental variables condition for instance; $\operatorname{cov}(z, u)=0, \operatorname{cov}(z$, $x) \neq 0$. If both conditions are not problematic then instrumental variables is strong. When the instrumental variables are weak, the 2SLS or IV estimators could be inconsistent or have large standard errors.

\section{Results and Discussion}

Data on the selected region characteristics are presented in Table 2. Country-level estimates show that the Nepal has the highest Remittance $(21.66 \%)$, followed by the Bangladesh (10.81\%), Sri Lanka (8.32\%) and India and Pakistan has small number in the Figure 1. On the other hand, except Nepal and Bangladesh all other countries show very less variation in education and health spending in last two decades. Same as, total populations in South Asian countries grow continuously with an increasing rate. Data on the summary statistics for each of the dependent and independent 
are presented in Table 2 .

Estimation results for one educational and three health variables are provided in Tables 3 and 4 . Table 3 presents the random effects GLS estimates, Table 4 presents the estimates from the 2SLS instrumental variables approach. Random effects GLS estimates have some econometric problem in regression such as high $\mathrm{R}^{2}$ and some variable are insignificant etc. For this reason, we focused on the results from the 2SLS estimates in Table 4 . The results 2SLS are mostly as per expectations except educational dependent variable. Comparing coefficients across the educational dependent variable, the key variable remittance was found insignificant in study. With respect to the health indicators, a remittance proves to be strong determinant for fertility rate, infant mortality rates and life expectancy variables.

We get unexpected results for the educational attainment for children but results of the study against the expectation. Reasons may be that; remittances are more likely to have a greater effect on secondary education, when there is greater tendency for older children to leave school to work (Zhunio et al., 2012). We expect that remittances are more likely to affect educational outcomes for older children where opportunity costs in terms of labor effort are higher. Further, our overall findings suggest that a higher level of remittances escalate life expectancy and reduces fertility and infant mortality rate.

As shown by the regression output in column 1 in Table 4, GDP is positively correlated with a community education attainment. GDP is significant at $1 \%$ and remittance is significant $5 \%$, respectively. On the other hand, educational expenditure and rural population, unemployment rate, infant mortality and time trend variables are negatively correlated with education at different levels but remittance is positive significant in educational model.

In column 2 results are the expected ones, remittance, GDP are positively correlated with communities life expectancy and number of physicians and ruler population are negative correlated with communities life expectancy but public health expenditures, unemployment rate and time effect is insignificant in case South Asia region. In column 3 numbers of physicians and ruler population are positively significant and remittance and GDP, public health expenditures, number of physicians, and unemployment rate are negatively significant at highly levels with communities infant mortality. In this case there is rural population variable is negative significant. Finally, it is also alluring to note that, the number of physicians and rural population are positively related to the fertility rate but remittances, GDP, public health expenditures unemployment rate and time trend coefficients are remain negative and significant with communities fertility rate at different levels.
Besides the important role of remittances in explaining education and health outcomes, higher GDP, unemployment rate and rural population led to improved educational index. Further, the regional variables and time trend all confirm to expectations. Same as, higher remittances, GDP, health expenditures and number of physicians infant mortality rate have a positively significant role in health determinants. In short, our overall findings suggest that a higher level of remittances have significant effect on education but increases life expectancy and reduces infant mortality rates and fertility rate.

\section{Conclusion}

Using a sample of South Asian countries, our analysis concludes that the results from regional studies on the relationship between remittances and development outcomes such as education and health are robust after controlling for economic characteristics (GDP per capita, rural population, public expenditures on education and health, Number of Physicians, unemployment rate) and time trends. For many countries, including South Asia, remittances are among the most important sources of external financing and this instrument proves to be a strong correlated with development indicators (Abbasi and Hashmi, 2000; Acosta et al., 2007; Amuedo-Dorantes and Pozo, 2011; Frank and Hummer, 2002; Lu and Treiman, 2007). A higher level of real remittances is correlated with life expectancy, lower infant mortality and lower fertility but insignificant with education.

In our region, there are limited studies that highlight the role of remittances on the education and health outcomes. Migrant income has grown swiftly in current years and remittances have showed a stable additional source of external finance. According to the literature, the consequence of remittances on education is also ambiguous. Therefore, children who live in remittance-receiving households complete more years of education than other children but in case of South Asian regions remittances no importance has been observed for average year of schooling. Similarly, this instruments improved health status particularly Life Expectancy, Infant mortality and Fertility rate of the family members.

\section{References}

Abbasi, S.-U.-R. S. and Hashmi, A. H. (2000). Migrants earning at overseas job and extent of remittances transferred to their families in pakistan. International Journal of Agriculture and Biology, 2(3):222-25.

Acosta, P., Fajnzylber, P., and Lopez, J. H. (2007). The impact of remittances on poverty and human capital: evidence from Latin 
American household surveys, volume 4247. World Bank Publications.

Amuedo-Dorantes, C. and Pozo, S. (2006). Migration, remittances, and male and female employment patterns. American Economic Review, 96(2):222-226.

Amuedo-Dorantes, C. and Pozo, S. (2011). Remittances and income smoothing. American Economic Review, 101(3):58287.

Baltagi, B. (2008). Econometric analysis of panel data. John Wiley \& Sons.

C $\tilde{A}^{3}$ rdova, E. L. et al. (2004). Globalization, migration and development: The role of mexican migrant remittances. In Econometric Society 2004 Latin American Meetings, number 82 . Econometric Society.

Calero, C., Bedi, A. S., and Sparrow, R. (2009). Remittances, liquidity constraints and human capital investments in ecuador. World Development, 37(6):1143-1154.

Córdova, J. E. L. (2006). Globalization, migration and development: the role of Mexican migrant remittances (Working Paper ITD = Documento de Trabajo ITD; $n$. 20), volume 20. BIDINTAL.

Dhungana, A. R. and Pandit, D. (2014). Socio-economic impact of remittance on households in lekhnath municipality, kaski, nepal. Economic Literature, 12:39-49.

Duryea, S., López-Córdova, E., and Olmedo, A. (2005). Migrant remittances and infant mortality: Evidence from mexico. Washington: Inter-American Development Bank. Mimeo.

Dustmann, C. and Glitz, A. (2011). Migration and education. In Handbook of the Economics of Education, volume 4, pages 327-439. Elsevier.

Elbadawy, A., Roushdy, R., et al. (2009). Impact of international migration and remittances on child schooling and child work: The case of egypt. Population Council Working Papers, 454.

Frank, R. and Hummer, R. A. (2002). The other side of the paradox: The risk of low birth weight among infants of migrant and nonmigrant households within mexico. International Migration Review, 36(3):746-765.

Grossman, M. (1972). On the concept of health capital and the demand for health. Journal of Political economy, 80(2):223255 .

Gupta, S., Pattillo, C., and Wagh, S. (2007). Making remittances work for africa. Finance and development, 44(2):1-8.

Hausman, J. A. (1978). Specification tests in econometrics. Econometrica: Journal of the econometric society, pages 12511271.
Hildebrandt, N. and McKenzie, D. J. (2005). The effects of migration on child health in Mexico. The World Bank.

Ilahi, N. (2001). Children's work and schooling: Does gender matter? evidence from the peru lsms panel data. working paper.

Jensen, P. and Nielsen, H. S. (1997). Child labour or school attendance? evidence from zambia. Journal of population economics, 10(4):407-424.

Jongwanich, J. (2007). Workers' remittances, economic growth and poverty in developing Asia and the Pacific countries. United Nations Publications.

Kabki, M., Mazzucato, V., and Appiah, V. (2003). The economic impact of remittances of holland based ghanaian migrants on rural ashanti. Brighton, Centre For Migration Research, University Of Sussex, Holland.

Lu, Y. and Treiman, D. J. (2007). The effect of labor migration and remittances on children's education among blacks in south africa.

McKenzie, D. and Rapoport, H. (2006). Can migration reduce educational attainment? Evidence from Mexico. The World Bank.

Ratha, D. (2013). The impact of remittances on economic growth and poverty reduction. Policy Brief, 8(1):1-13.

Schiantarelli, F. (2005). Global economic prospects 2006: economic implications of remittances and migration. The World Bank

Stark, O., Taylor, J. E., and Yitzhaki, S. (1988). Migration, remittances and inequality: A sensitivity analysis using the extended gini index. Journal of Development Economics, 28(3):309-322.

Taylor, J. E. and Wyatt, T. J. (1996). The shadow value of migrant remittances, income and inequality in a household-farm economy. The Journal of Development Studies, 32(6):899-912.

Wahba, S. (1996). Temporary labour migration in egyptian agricultural households: Implications for gender differences in school enrolment. Forum.

Wooldridge, J. M. (2010). Econometric analysis of cross section and panel data. MIT press.

Yang, D. (2005). International migration, human capital, and entrepreneurship: evidence from Philippine migrants' exchange rate shocks. The World Bank.

Zhunio, M. C., Vishwasrao, S., and Chiang, E. P. (2012). The influence of remittances on education and health outcomes: a cross country study. Applied Economics, 44(35):4605-4616. 